\title{
Circulating Anti-Glomerular Basement Membrane Antibodies With Predominance of Subclass IgG4 and False-Negative Immunoassay Test Results in Anti-Glomerular Basement Membrane Disease
}

\author{
Sophie Ohlsson, Hans Herlitz, Sigrid Lundberg, Daina Selga, Johan Molne, Jorgen \\ Wieslander and Mårten Segelmark
}

\section{Linköping University Post Print}

\section{Tweet}

N.B.: When citing this work, cite the original article.

Original Publication:

Sophie Ohlsson, Hans Herlitz, Sigrid Lundberg, Daina Selga, Johan Molne, Jorgen Wieslander and Mårten Segelmark, Circulating Anti-Glomerular Basement Membrane Antibodies With Predominance of Subclass IgG4 and False-Negative Immunoassay Test Results in Anti-Glomerular Basement Membrane Disease, 2014, American Journal of Kidney Diseases, (63), 2, 289-293.

http://dx.doi.org/10.1053/j.ajkd.2013.08.032

Copyright: Elsevier http://www.elsevier.com/

Postprint available at: Linköping University Electronic Press http://urn.kb.se/resolve?urn=urn:nbn:se:liu:diva-104282 
Circulating Anti-Glomerular Basement Membrane Antibodies with Predominance of Subclass IgG4 and False Negative Immunoassay Test Results in Anti-GBM Disease Sophie Ohlsson $\mathrm{MD}^{1}$, Hans Herlitz $\mathrm{MD}^{2}$, Sigrid Lundberg $\mathrm{MD}^{3}$, Daina Selga MD ${ }^{1}$, Johan Mölne $\mathrm{MD}^{4}$, Jörgen Wieslander PhD ${ }^{5}$, Mårten Segelmark MD ${ }^{6,7}$.

${ }^{1}$ Department of Nephrology and Transplantation, Skane University Hospital, ${ }^{2}$ Department of Nephrology, Sahlgrenska University Hospital, Göteborg, ${ }^{3}$ Department of Nephrology, Karolinska University Hospital, Stockholm, ${ }^{4}$ Department of Pathology, Sahlgrenska University Hospital, Göteborg, ${ }^{5}$ Eurodiagnostica AB, Malmö, ${ }^{6}$ Department of Medical and Health Sciences, Linköping University, ${ }^{7}$ Department of Nephrology, County Council of Östergötland, Linköping, Sweden.

Corresponding author: Mårten Segelmark

Postal address: Division of Drug Research/Nephrology, Department of Medical and Health Sciences, Linköping University, 58185 Linköping, Sweden

Telephone: +46-101032297, telefax: +46-13149106

E-mail: marten.segelmark@liu.se

Word count: abstract -165 words; main body- 1523

Short title: Anti-GBM disease with predominance of IgG4 


\section{Support and Financial Disclosure Declaration}

This work was supported by grants from the Swedish Kidney Foundation and the Ingrid Asp Foundation (MS).

JW is employed by Eurodiagnostica, a company marketing kits for anti-GBM analysis. No other author has any disclosures to make.

\section{Abstract}

Autoantibodies against a constituent of the glomerular basement membrane (GBM), the $\alpha 3$-chain of type IV collagen, can cause both rapidly progressive glomerulonephritis and alveolar hemorrhage, referred to as anti-GBM disease or Goodpasture's disease. Anti-GBM antibodies are generally of immunoglobulin G subclass 1 (IgG1) and can in most cases readily be detected in the circulation using enzyme linked immunosorbent assays (ELISA).

Here we report 4 cases where anti-GBM ELISA yielded negative or borderline results despite lifethreatening disease. All four patients were positive in IgG4 anti-GBM ELISA and all were ANCA negative. All cases were confirmed with kidney biopsy. Two of the patients exhibited higher results in anti-GBM ELISA when using a non-denaturing coating buffer. All four were young women with severe alveolar hemorrhage and favorable renal outcome suggesting that patients with predominance of IgG4 autoantibodies may constitute a distinct subgroup of anti-GBM disease.

We conclude that patients with idiopathic alveolar hemorrhage can have anti-GBM disease detected only by IgG subclass specific tests or by kidney biopsy. 


\section{Introduction}

Anti-glomerular basement membrane (anti-GBM) disease, also called Goodpasture's disease, is characterized by auto-antibodies specific for the $\alpha 3$-chain of type IV collagen ${ }^{1}$. It usually presents as rapidly progressive glomerulonephritis, with or without alveolar hemorrhage $(\mathrm{AH})^{2,3}$. The relative severity and the temporal relationship between renal and pulmonary disease varies among patients. A small minority are diagnosed with normal kidney function despite severe $\mathrm{AH}^{4}$.

Anti-GBM antibodies can normally be detected in the circulation by enzyme linked immunosorbent assay (ELISA) ${ }^{5}$. They are mostly of subclass IgG1, though other IgG subclasses can be found $d^{6-9}$. We here report 4 young women with severe $\mathrm{AH}$ and anti-GBM antibodies predominantly of subclass IgG4, who exhibited low or negative results in regular anti-GBM ELISA.

\section{Case 1}

A 43 year-old woman, current smoker, presented with acute respiratory insufficiency. Four years earlier she had been treated at another hospital under the diagnosis of atypical pneumonia with hemolytic anemia. She had anemia, cough, hemoptysis and microscopic hematuria, which all resolved during treatment with antibiotics, steroids and azathioprine.

At the present admission C-reactive protein (CRP) was $51 \mu \mathrm{g} / \mathrm{mL}$ and hemoglobin (Hb) $10.7 \mathrm{~g} / \mathrm{dL}$. Chest X-ray demonstrated profuse alveolar alterations. A day oxygen saturation $\left(\mathrm{SaO}_{2}\right)$ fell to $86 \%$ and chest X-ray showed progression. Creatinine remained normal, but $\mathrm{Hb}$ decreased to $6.8 \mathrm{~g} / \mathrm{dL}$ and her clinical condition continued to worsen. Bronchoscopy revealed profuse peripheral airway bleeding. Screening ELISA was positive for anti-GBM, however, quantitative ELISA was negative ${ }^{10}$. To sort out the discrepancy, more detailed investigations were done. IgM and IgA against GBM were negative along with IgG1, IgG2 and IgG3; however, anti-GBM of subclass IgG4 was positive ${ }^{7}$. When a physiological non-denaturing coating buffer (phosphate buffered saline) was used instead of the standard denaturing guanidine buffer the IgG4 reactivity increased substantially. Kidney biopsy 
showed normal histology, but immunofluorescence displayed linear staining for IgG and C3. Her condition improved and after a month she was discharged. Intravenous cyclophosphamide was followed by oral azathioprine for more than 2 years.

\section{Case 2}

A 21 year-old woman, current smoker, sought medical attention at multiple occasions because of persistent cough with blood tinted expectorate. Treatment with antibiotics had no effect. At her third visit $\mathrm{Hb}$ of $7.7 \mathrm{~g} / \mathrm{dl}$ and creatinine of $15.1 \mathrm{mg} / \mathrm{dl}$ was detected. A CT scan indicated AH. Screening ELISA was positive for anti-GBM, but quantitative ELISA was negative. Extended anti-GBM analysis was negative for $\lg A$, $\lg M, \lg G 2$ and 3; positive for $\lg G 1$ and strongly positive for IgG4. Kidney biopsy showed cellular crescents in 18 out of 28 glomeruli and linear immunofluorescence for lgG.

Two weeks after start of treatment her condition suddenly deteriorated, with acute dyspnea and $\mathrm{SaO}_{2} 62 \%$. Bronchoscopy samples were positive for influenza virus $\mathrm{B}$ and zanamivir was given. Her condition stabilized, kidney function improved and peritoneal dialysis was stopped after 3 months.

\section{Case 3}

A 22 year-old woman sought medical attention because of progressive fatigue. Blood tests revealed $\mathrm{Hb} 5.6 \mathrm{~g} / \mathrm{dL}$. After a work-up including renal ultrasound, gastroscopy and colonoscopy, a diagnosis of iron deficiency was made and she was discharged with supplement.

A month later she was re-admitted because of nausea, episodes of macroscopic hematuria and creatinine of $1.92 \mathrm{mg} / \mathrm{dL}$. ELISA was positive for anti-GBM and 2 days later she developed hemoptysis. When standard ELISA turned negative plasmapheresis was discontinued. However, her kidney function continued to deteriorate. After two months a second kidney biopsy showed fresh cellular crescents (Figure 1). Determination of IgG subclasses of anti-GBM revealed positive results for IgG4, but negative results for all other subclasses. Plasmapheresis was restarted and creatinine peaked at $5.4 \mathrm{mg} / \mathrm{dL}$. At discharge creatinine was $2.8 \mathrm{mg} / \mathrm{dL}$. 


\section{Case 4}

An 18 year-old non-smoking woman was admitted because of hemoptysis. One month earlier she had received antibiotics due to dyspnea and subfertility. On admission tests revealed $\mathrm{Hb} 7.9 \mathrm{~g} / \mathrm{dL}$, CRP $102 \mu \mathrm{g} / \mathrm{mL}$, creatinine $0.92 \mathrm{mg} / \mathrm{dL}$ and dipstick hematuria. A thoracic CT scan showed extensive bilateral symmetric nodular infiltrates. ELISA for anti-GBM was slightly above the detection limit.

Plasmapheresis and treatment with cyclophosphamide pulses and steroids was started. A repeated analysis of anti-GBM antibodies 2 days after diagnosis was negative but anti-GBM IgG4 was positive. When using a non-denaturing coat an increase in reactivity was seen. The AH ceased and IgG4antibody tests turned negative. Proteinuria peaked at $0.5 \mathrm{~g} / 24$ hours. Kidney biopsy showed focal necrotizing lesions in 5 out of 50 glomeruli. Immunofluorescence was positive for IgG in a linear pattern. Six months later s-creatinine was $0.69 \mathrm{mg} / \mathrm{dl}$ and albuminuria within normal range, but microhematuria persisted.

Despite ongoing treatment with azathioprine, the patient relapsed with $\mathrm{AH}$ accompanied by mild urinary abnormalities 15 months after the initial diagnosis. All antibody tests were negative including IgG subclasses of anti-GBM. Immunosuppressive treatment was restarted, AH resolved and renal function remained normal.

\section{Discussion}

These four patients demonstrate that predominance of subclass IgG4 of anti-GBM can be a cause for false negative tests. Cases of anti-GBM disease without detectable circulating antibodies have been seen in many series ${ }^{5}$. There are several possible reasons for negative test results. The half-life of kidney bound antibodies is longer than the half-life for those in the circulation, and thus circulating antibodies may have disappeared when the serum sample is drawn. However, Salama and coworkers were able to demonstrate circulating antibodies in two patients using biosensor technique, even though both ELISA and Western blot analysis were negative ${ }^{11}$. Another possible explanation for 
false negative results is autoantibodies reacting with a different antigen or epitopes as compared with "regular" anti-GBM antibodies, that all react with two well defined epitope regions of the NC1domain of Type IV collagen $\alpha 3$-chains ${ }^{12}$. Such findings were recently described in four Chinese patients with biopsy proven anti-GBM disease, and have been described in patients with IgA anti$\mathrm{GBM}^{13-15}$. A better reactivity when using the non-denaturing coating conditions in two of the present cases indicate that epitope differences do contribute to the low test results in our patients. However, the major reason for the false negative results is most probably a reduced ability of some antisera to recognize the human $\mathrm{p4}$-chain.If so the problem to detect IgG4 autoantibodies may not be restricted to anti-GBM testing.

There are other common features between these four cases, raising the possibility that anti-GBM disease with IgG4 predominance constitutes a distinct clinical subgroup, as suggested by Cui et al ${ }^{16}$. All of them were relatively young women, they had severe pulmonary disease, all were ANCA negative, all had preserved kidney function on follow-up and two have experienced relapses. In the early case series as well as in recent Chinese studies there is a strong male preponderance $e^{17,18}$. Other recent series tend to show a more even sex distribution ${ }^{2,19}$. In our 1991 study on anti-GBM subclasses we had no patients with predominance of $\lg G 4$, but we found that high $\lg G 4$ was more common in women ${ }^{7}$. This finding was, however, not confirmed by Cui et al ${ }^{8}$. Anti-GBM disease has been shown to have a bimodal age distribution, with one peak around 20 and a second peak between 60 and $70^{19}$. In our study the median age at diagnosis was 60 years, considerably higher than the age of the present cases ${ }^{2}$. ANCA-positivity is more common among elderly anti-GBM patients ${ }^{20}$.

All the present cases had life-threatening $\mathrm{AH}$. In our Swedish series we found overt hemoptysis in only $23 \%^{2}$, but other studies report higher figures ${ }^{3,21,22}$. Smoking has repeatedly been linked to pulmonary engagement in anti-GBM disease $\mathrm{e}^{23}$ and three of our patients were current smokers, but the severity of the lung disease in the current cases is intriguing. The limited capacity of IgG4 to bind 
complement and engage Fc receptors on neutrophils raises questions regarding their pathogenic potential. Bowman et al reported on a patient where no clinical symptoms were seen when IgG4 anti-GBM antibodies reappeared four years after diagnosis ${ }^{6}$. However, recently there has been a growing interest in IgG4 related autoimmune syndromes ${ }^{24}$. Other autoantibodies of subclass IgG4 in organ specific autoimmune diseases, such as bullous pemphigoid and membranous nephropathy, have been shown to harbor pathogenic potential ${ }^{9,25,26}$. Beck et al have shown that IgG4 anti-PLA2R activates the lectin pathway of complement due to defects in glycosylation ${ }^{27}$.

All patients in the present series had functioning native kidneys. This was the case in only $20 \%$ of our Swedish series and even less in the studies from Beijing ${ }^{2,28}$. Interestingly the case with IgG4 anti-GBM reported by Cui also had mild kidney disease ${ }^{16}$; and in a French study ${ }^{23} 5$ of 13 cases with alveolar hemorrhage and normal kidney function had no detectable anti-GBM in the circulation. It is possible that differences in epitope specificity and/or in engagement of inflammatory effector systems account for the differences in phenotype between our patients with IgG4 anti-GBM and patients with "regular" IgG1 anti-GBM. Two the of the four patients have relapsed, late relapses are rare in antiGBM disease, we found 1 case out of 81 while Levy et al found 2 among $71^{22,29}$.

In summary our cases demonstrate that negative testing for circulating anti-GBM antibodies do not rule out the possibility of anti-GBM disease and that IgG4 autoantibodies is a possible cause of false negative testing. Whether this finding is more common in patients with the combination of severe lung disease and mild kidney disease remains to be determined. 
Table 1. Selected clinical data from 4 patients with anti-GBM disease and autoantibodies predominantly of subclass IgG4.

\begin{tabular}{|c|c|c|c|c|}
\hline Patient & 1 & 2 & 3 & 4 \\
\hline Sex & $\mathrm{F}$ & $\mathrm{F}$ & $\mathrm{F}$ & $\mathrm{F}$ \\
\hline Age (years) & 43 & 21 & 22 & 18 \\
\hline $\begin{array}{l}\text { Max creatinine } \\
(m g / d L)\end{array}$ & 1.0 & 21.9 & 5.4 & 0.92 \\
\hline $\begin{array}{l}\text { Creatinine at } 6 \text { month } \\
(\mathrm{mg} / \mathrm{dL})\end{array}$ & 0.90 & 0.85 & 2.5 & 0.69 \\
\hline $\operatorname{Min} H b g / d L$ & 6.8 & 7.7 & 5.6 & 7.9 \\
\hline Lung hemorrhage & +++ & +++ & +++ & +++ \\
\hline Kidney biopsy & $\begin{array}{l}\text { Normal } \\
\text { glomeruli }\end{array}$ & $\begin{array}{l}\text { Crescentic GN } \\
18 / 28 \text { glomeruli }\end{array}$ & $\begin{array}{l}\text { Crescentic GN } \\
25 / 25 \text { glomeruli }\end{array}$ & $\begin{array}{c}\text { Focal GN } \\
5 / 50 \text { glomeruli }\end{array}$ \\
\hline Immunofluorescence & Linear IgG & Linear IgG & Linear IgG & Linear IgG \\
\hline Total IgG-anti-GBM ** & 3 & 12 & $32 / 0^{*}$ & 4 \\
\hline IgG1-anti-GBM** & 0 & 7 & $2 / 0^{*}$ & 0 \\
\hline IgG2-anti-GBM** & 0 & 0 & $3 / 0^{*}$ & 0 \\
\hline IgG3-anti-GBM** & 0 & 0 & $5 / 0^{*}$ & 0 \\
\hline IgG4-anti-GBM** & 33 & 28 & $100 / 14^{*}$ & 9 \\
\hline MPO-ANCA & neg & neg & neg/neg* & neg \\
\hline PR3-ANCA & neg & neg & neg/neg* & neg \\
\hline Treatment & $\begin{array}{l}\text { PLEX, CYC iv, } \\
\text { pred*** }^{*}\end{array}$ & $\begin{array}{c}\text { PLEX, CYC iv, } \\
\text { pred }^{* * *}\end{array}$ & $\begin{array}{l}\text { PLEX, CYC iv, } \\
\text { pred*** }^{* * *}\end{array}$ & $\begin{array}{l}\text { PLEX, CYC iv, } \\
\text { pred*** }^{*}\end{array}$ \\
\hline
\end{tabular}

* Sample sent to the reference laboratory at the time of the second kidney biopsy

$* *$ Normal ranges in the assays are: total IgG <10; IgG1 <3; IgG2<8; $\operatorname{lgG}<<27$; IgG4<7 ELISA units.

*** PLEX = plasma exchange, $\mathrm{CYC}$ iv $=$ inter mitten intravenous cyclophosphamide, pred $=$ prednisolone

\section{Figures legend}

Figure 1

A. PAS stained light microscopy sample from the second biopsy of patient 3, showing crescentic nephritis.

B. Immunperoxidase staining of the same biopsy using anti-IgG, showing linear flourescense. 
A.

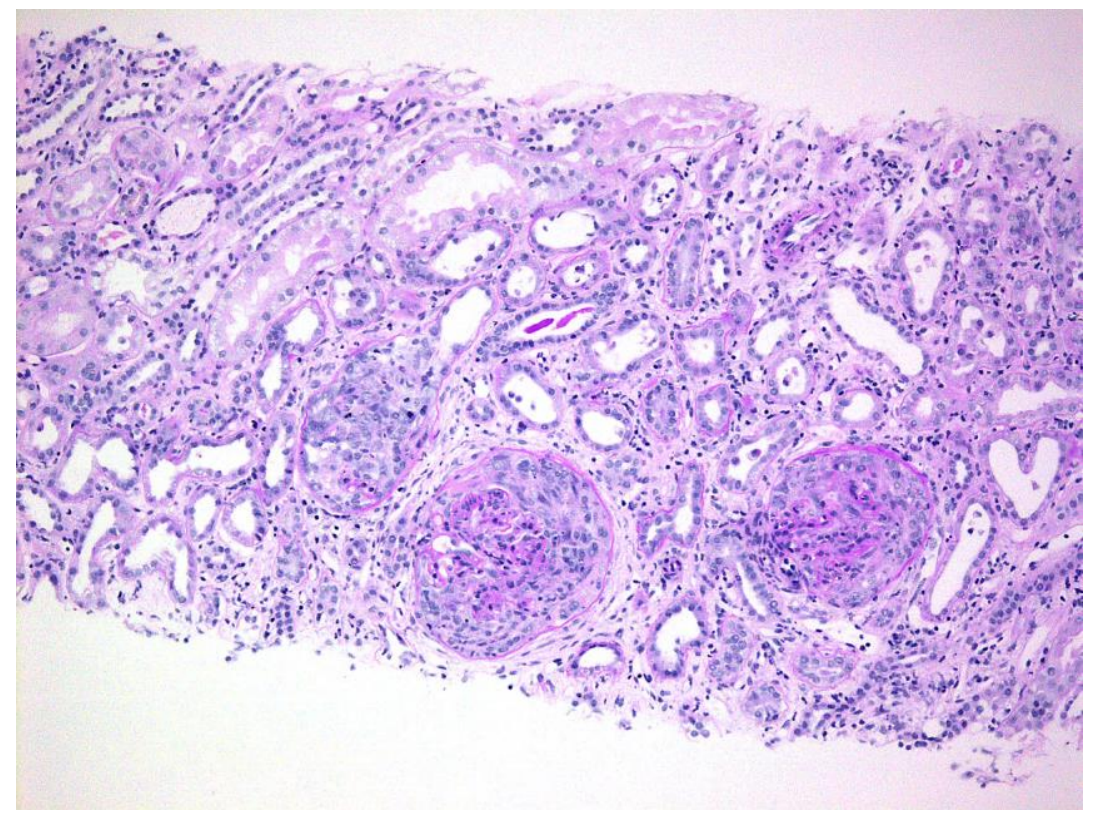

B.

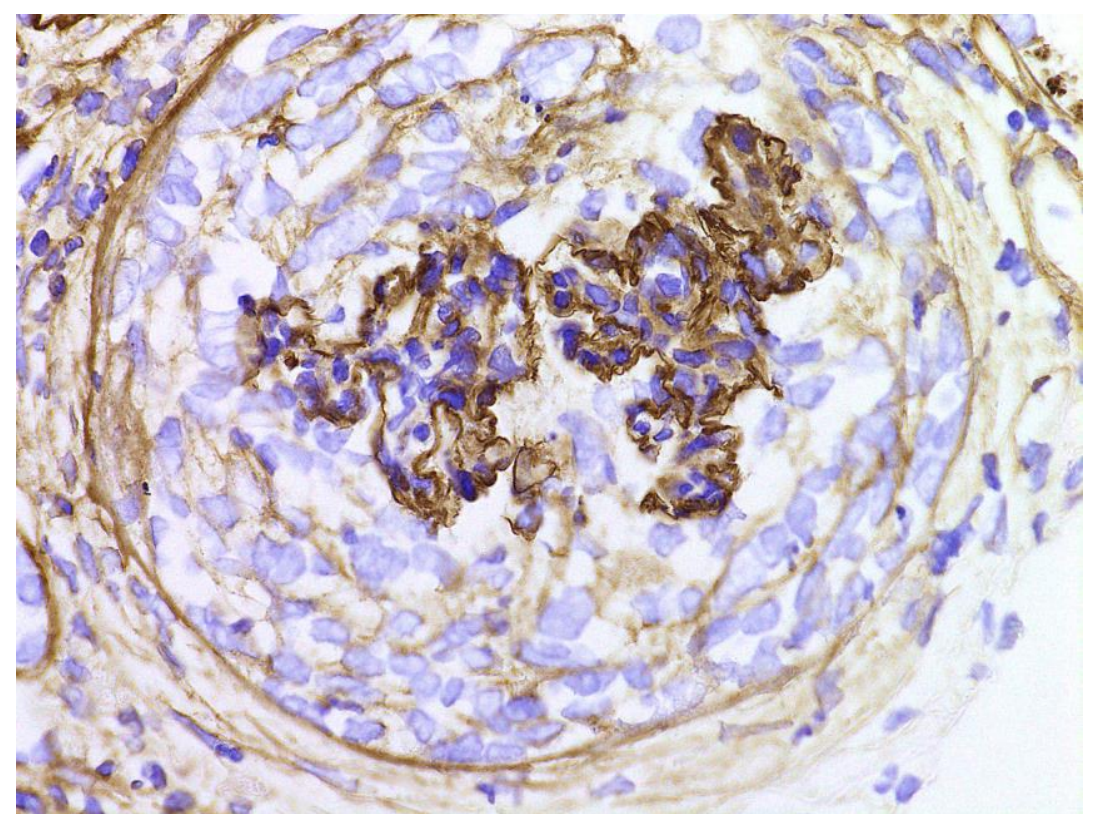

References

1. Pusey CD. Anti-glomerular basement membrane disease. Kidney Int. Oct 2003;64(4):1535-1550.

2. Segelmark M, Hellmark T, Wieslander J. The prognostic significance in Goodpasture's disease of specificity, titre and affinity of anti-glomerularbasement-membrane antibodies. Nephron Clin Pract. 2003;94(3):c59-68. 
3. Cui Z, Zhao MH, Xin G, Wang HY. Characteristics and prognosis of Chinese patients with anti-glomerular basement membrane disease. Nephron. Clinical practice. 2005;99(2):c49-55.

4. Le Quang C, Delevaux I, Trouillier S, et al. [Intra-alveolar haemorrhage without renal damage as the initial presenting feature of Goodpasture's syndrome: case report and review of literature]. Rev Med Interne. Dec 2008;29(12):1038-1042.

5. Sinico RA, Radice A, Corace C, Sabadini E, Bollini B. Anti-glomerular basement membrane antibodies in the diagnosis of Goodpasture syndrome: a comparison of different assays. Nephrol Dial Transplant. Feb 2006;21(2):397-401.

6. Bowman C, Ambrus K, Lockwood CM. Restriction of human IgG subclass expression in the population of auto-antibodies to glomerular basement membrane. Clin Exp Immunol. Aug 1987;69(2):341-349.

7. Segelmark M, Butkowski R, Wieslander J. Antigen restriction and IgG subclasses among anti-GBM autoantibodies. Nephrol Dial Transplant. 1990;5(12):991-996.

8. Zhao J, Yan Y, Cui Z, Yang R, Zhao MH. The immunoglobulin G subclass distribution of anti-GBM autoantibodies against rHalpha3(IV)NC1 is associated with disease severity. Hum Immunol. Jun 2009;70(6):425-429.

9. Noel LH, Aucouturier P, Monteiro RC, Preud'Homme JL, Lesavre P. Glomerular and serum immunoglobulin $G$ subclasses in membranous nephropathy and anti-glomerular basement membrane nephritis. Clin Immunol Immunopathol. Feb 1988;46(2):186-194.

10. Westman KW, Bygren PG, Eilert I, Wiik A, Wieslander J. Rapid screening assay for anti-GBM antibody and ANCAs; an important tool for the differential diagnosis of pulmonary renal syndromes. Nephrol Dial Transplant. Sep 1997;12(9):1863-1868.

11. Salama AD, Dougan T, Levy JB, et al. Goodpasture's disease in the absence of circulating anti-glomerular basement membrane antibodies as detected by standard techniques. Am J Kidney Dis. Jun 2002;39(6):1162-1167.

12. Hellmark T, Segelmark M, Wieslander J. Anti-GBM antibodies in Goodpasture syndrome; anatomy of an epitope. Nephrol Dial Transplant. Apr 1997;12(4):646648.

13. Jia XY, Qu Z, Cui Z, Yang R, Zhao J, Zhao MH. Circulating anti-glomerular basement membrane autoantibodies against alpha3(IV)NC1 undetectable by commercially available enzyme-linked immunosorbent assays. Nephrology (Carlton). Feb 2012;17(2):160-166.

14. Borza DB, Chedid MF, Colon S, Lager DJ, Leung N, Fervenza FC. Recurrent Goodpasture's disease secondary to a monoclonal IgA1-kappa antibody autoreactive with the alpha1/alpha2 chains of type IV collagen. Am J Kidney Dis. Feb 2005;45(2):397-406.

15. Ho J, Gibson IW, Zacharias J, Fervenza F, Colon S, Borza DB. Antigenic heterogeneity of IgA anti-GBM disease: new renal targets of IgA autoantibodies. Am J Kidney Dis. Oct 2008;52(4):761-765.

16. Cui Z, Zhao MH, Singh AK, Wang HY. Antiglomerular basement membrane disease with normal renal function. Kidney Int. Dec 2007;72(11):1403-1408.

17. Teague CA, Doak PB, Simpson IJ, Rainer SP, Herdson PB. Goodpasture's syndrome: an analysis of 29 cases. Kidney Int. Jun 1978;13(6):492-504.

18. Briggs WA, Johnson JP, Teichman S, Yeager HC, Wilson CB. Antiglomerular basement membrane antibody-mediated glomerulonephritis and Goodpasture's syndrome. Medicine (Baltimore). Sep 1979;58(5):348-361. 
19. Savage CO, Pusey CD, Bowman C, Rees AJ, Lockwood CM. Antiglomerular basement membrane antibody mediated disease in the British Isles 1980-4. Br Med J (Clin Res Ed). Feb 1 1986;292(6516):301-304.

20. Yang R, Hellmark T, Zhao J, et al. Antigen and epitope specificity of antiglomerular basement membrane antibodies in patients with goodpasture disease with or without anti-neutrophil cytoplasmic antibodies. J Am Soc Nephrol. Apr 2007;18(4):1338-1343.

21. Taylor DM, Yehia M, Simpson IJ, Thein H, Chang Y, de Zoysa JR. Antiglomerular basement membrane disease in Auckland. Intern Med J. Jun 2012;42(6):672-676.

22. Levy JB, Turner AN, Rees AJ, Pusey CD. Long-term outcome of anti-glomerular basement membrane antibody disease treated with plasma exchange and immunosuppression. Ann Intern Med. Jun 5 2001;134(11):1033-1042.

23. Lazor R, Bigay-Game L, Cottin V, et al. Alveolar hemorrhage in anti-basement membrane antibody disease: a series of 28 cases. Medicine (Baltimore). May 2007;86(3):181-193.

24. Stone JH, Zen Y, Deshpande V. IgG4-related disease. $N$ Engl J Med. Feb 9 2012;366(6):539-551.

25. Bernard P, Aucouturier P, Denis F, Bonnetblanc JM. Immunoblot analysis of IgG subclasses of circulating antibodies in bullous pemphigoid. Clin Immunol Immunopathol. Mar 1990;54(3):484-494.

26. Khosroshahi A, Ayalon R, Beck LH, Jr., Salant DJ, Bloch DB, Stone JH. IgG4Related Disease Is Not Associated with Antibody to the Phospholipase A2 Receptor. Int J Rheumatol. 2012;2012:139409.

27. Ma HB, L.H.; Salant, D.J. Membranous Nephropathy-Associated AntiPhospholipase A2 Receptor IgG4 Autoantibodies Activate the Lectin Complement Pathway. J Am Soc Nephrol. 2011;22:62A.

28. Yang R, Hellmark T, Zhao J, et al. Levels of epitope-specific autoantibodies correlate with renal damage in anti-GBM disease. Nephrol Dial Transplant. Jun 2009;24(6):1838-1844.

29. Segelmark M, Hellmark T, Wieslander J. The prognostic significance in Goodpasture's disease of specificity, titre and affinity of anti-glomerularbasement-membrane antibodies. Nephron. Clinical practice. 2003;94(3):c59-68. 